Revista Destaques Acadêmicos, Lajeado, v. 9, n. 1, 2017. ISSN 2176-3070 DOI: http://dx.doi.org/10.22410/issn.2176-3070.v9i1a2017.1257 www.univates.br/revistas

\title{
ANÁLISE DA VIABILIDADE DE INVESTIMENTO PELO MODELO TRADICIONAL E ESTOCÁSTICO EM ATIVIDADE AVÍCOLA
}

\author{
Juliana Gabiatti ${ }^{1}$, Alexandre André Feil ${ }^{2}$
}

\begin{abstract}
Resumo: A análise consistente que precede o investimento pode ser considerada o diferencial do sucesso do empreendimento. Neste contexto, o objetivo deste estudo é analisar a viabilidade de investimento na produção de frango de corte em propriedade de Westfália-RS, por meio do método tradicional e estocástico. A metodologia empregada é a abordagem quantitativa e os procedimentos técnicos caracterizados pela pesquisa documental primária e entrevista despadronizada. Os resultados relativos à análise tradicional - três cenários - revela apenas o fluxo de caixa projetado no cenário otimista viável. A análise estocástica por meio do Método Monte Carlo - software Crystal Ball revela resultados e/ou informações mais precisos, sendo que a probabilidade do VPL ser positivo e do investimento ser viável é de $8 \%$. Portanto, conclui-se que as informações geradas pela análise estocástica são consistentes e auxiliam potencialmente na tomada de decisão sobre o investimento, e que deve ser utilizada como um complemento na análise tradicional. Sendo assim, este investimento caracteriza-se como inviável.
\end{abstract}

Palavras-chave: Análise de investimento. Método Monte Carlo. Riscos e Incertezas. Crystal Ball.

\section{INTRODUÇÃO}

A análise de viabilidade econômica e financeira é um essencial precedente ao investimento de capital, pois pode verificar a consistência e a rentabilidade do projeto a ser implementado (ZAGO; WEISE; HORNBURG, 2009). A análise de viabilidade de um empreendimento, como ferramenta gerencial, também é quesito básico para tomar a decisão de investir e sobreviver no mercado (GIACOMIN, 2008), ademais busca apontar as vantagens do investimento (ZAGO; WEISE; HORNBURG, 2009). Portanto, avalia a viabilidade de um empreendimento, por meio de métodos tradicionais - Valor Presente Líquido

1 Acadêmica do Curso de Ciências Contábeis do Centro Universitário UNIVATES.

2 Doutor em Qualidade Ambiental pela Universidade Feevale. Docente adjunto do Centro Universitário UNIVATES alocado no curso de Ciências contábeis do CGO. 
(VPL), Taxa Interna de Retorno (TIR), Payback (PB), dentre outras - (PEDRAZZI; VIEIRA, 2009; ZANATA, 2012).

Os projetos de investimento devem ser avaliados por técnicas que analisem sua viabilidade, porém são pouco os métodos que consideram os riscos que envolvem os fluxos de caixa de um empreendimento, quando ocorre é pela sensibilidade, ou seja, simulação de resultados para vários custos de capital e/ ou taxa de crescimento de receitas (BRUNI; FAMÁ; SIQUEIRA, 1998). Amorim e Rocha (2011) concordam que os métodos tradicionais não consideram a incerteza sobre o futuro e as especificidades de cada investimento.

A alternativa ao método tradicional de análise de investimento é o Método de Monte Carlo (MMC), o qual associa distribuições de probabilidade as variáveis do projeto e pode assumir diversos valores ao invés de um único, quantificando as incertezas ao longo do tempo (OLIVEIRA; ALMEIDA; REBELATTO, 2009). O MMC pode ser simulado por meio de planilhas eletrônicas ou softwares específicos como o Crystal Ball (PAIXÃO; BRUNI; MARBACK, 2004).

As análises de investimentos podem ser realizadas no meio empresarial e agropecuário, em especial, no setor avícola, pelo aumento anual do consumo da carne de frango gerando constantes demandas de investimentos (ANDRADE, 2015). Na averiguação de um novo investimento é necessário analisar a viabilidade do mesmo, por meio de métodos científicos, pois tomar decisões de forma intuitiva é muito arriscado.

Neste contexto, o objetivo geral desse estudo é analisar a viabilidade de investimento na produção de frango de corte em propriedade de WestfáliaRS, por meio do método tradicional e estocástico. A justificativa deste estudo vem ao encontro que o Vale do Taquari-RS é responsável pela fatia de 30\% na produção da carne de frango do RS (ZANCHET, 2013). A avicultura de corte é responsável por diversos negócios e geração de renda para a região e, além disso, a análise de investimentos em propriedades rurais de pequeno e médio porte, visando sua continuidade, evita o êxodo rural ou até mesmo estimula o êxito urbano, o que minimiza problemas sociais, como desemprego (HOFER et al., 2011).

\section{REFERENCIAL TEÓRICO}

\subsection{Fluxo de Caixa (FC)}

O FC compreende as entradas e saídas de valores financeiros ao longo do projeto, assim é possível obter a rentabilidade e a viabilidade econômica do investimento (SAMANEZ, 2009). O FC é a principal ferramenta financeira e indispensável na avaliação da viabilidade financeira (CAMLOFFSKI, 2014). A projeção do FC reduz os riscos operacionais e financeiros e é necessário acompanhar se o fluxo projetado está se realizando, fazendo um comparativo 
entre o projetado e o realizado (CAMLOFFSKI, 2014). A elaboração do FC deve considerar as variáveis econômicas, políticas, tributárias, ambientais, legais, aspectos mercadológicos, dentre outros, por isso se torna difícil sua elaboração (CAMLOFFSKI, 2014).

A elaboração do FC necessita alguns cuidados, conforme Samanez (2009): a) os valores devem ser presumidos em base incremental resultantes do investimento; b) os custos de oportunidade devem ser destinados com eficiência; c) considerar as necessidades de mudança de capital de giro, pois afetam a decisão e são incrementais; d) considerar todos os efeitos advindos do investimento; e) Os valores que já foram injetados no investimento, que não serão recuperados se o mesmo não for executado, não devem ser incluídos no FC; f) Somente os custos incrementais devem ser alocados; g) o fluxo de financiamentos não deve compor o caixa livre; h) a inflação deve ser considerada; e i) estimar com coerência o valor residual do investimento.

As principais vantagens na projeção do FC são (ZDANOWICZ, 2010): a) Proporciona visão completa; b) Determina o ponto de equilíbrio de caixa; c) Propicia aos interessados uma visão clara a curto, médio e longo prazo; d) Serve de apoio para a direção na tomada de decisão; e) Permite traçar estratégias de vendas, compras e créditos; f) Possibilita direcionar prováveis sobras ou faltas de caixa, para opções mais atrativas; g) Estima a capacidade de pagamento; h) Permite comparar entradas e saídas; e i) Determina o melhor momento para realizar compras em função dos prazos de pagamento e da disponibilidade de caixa. As desvantagens do FC centram-se na geração de "[...] projeções incompletas e equivocadas na tomada de decisões; distorção dos valores projetados por fatores internos e externos não previsíveis, acarretando perdas econômicas e financeiras [...]" (ZDANOWICZ, 2010, p. 178).

\subsection{Análise de investimentos}

A análise de investimento é a utilização de técnicas específicas de princípios financeiros com propósito de apontar se é (in)viável a realização de determinado projeto (PEDRAZZI; VIEIRA, 2009; ZANATA, 2012). A análise de investimento busca gerar indicadores, os quais serão úteis na seleção de alternativas de empreendimentos (SOUZA; CLEMENTE, 2004). Esta análise, para Sousa (2007, p. 53) é "[...] reunir argumentos e informações para construir os fluxos de caixa esperados em cada um dos períodos da vida desse investimento e aplicar as técnicas que permitam evidenciar se as futuras entradas de caixa compensam a realização do investimento". As ferramentas de análise que podem ser utilizadas relacionam-se ao VP, VPL, VPLA, TIR, TIR-M, PB simples, PB descontado, PB total, PB TIR, PB TIR-M, IL, ROIA, TMR, TMA e MMC. 


\subsubsection{Valor Presente (VP), Valor Presente Líquido (VPL) e Valor Presente Líquido Anualizado (VPLA)}

O VP representa as entradas e saídas de um FC hoje, ou seja, desconta o custo do capital do investimento (LIMA; GIASSON, 2013) (EQUAÇÃO 1).

Valor Presente $(\mathrm{PV})=\frac{\text { Valor Futuro }}{(1+\mathrm{i})^{\mathrm{n}}}$

O VPL, Equação (2), traz a valor atual os fluxos de caixas gerados pelo investimento durante o longo de sua vida útil, se o VPL for positivo indica que o projeto é economicamente viável (SAMANEZ, 2009; ZAGO; WEISE; HORNBURG, 2009).

Valor Presente Líquido (VPL) = Investimento Inicial - Valor Presente

O VPL possui vantagens e desvantagens (SAMANEZ, 2009; SOUSA, 2007; FERREIRA, 2009; FREZATTI, 2008): a) vantagens: fácil entendimento e interpretação; retornos rápidos; fácil apuração e visualização gráfica; considera o valor no tempo; utiliza a taxa mínima de retorno estabelecida pelo investidor; e b) desvantagens: dificuldade na definição da taxa mínima; no caso de múltiplo investimentos com vida útil diferente deve definir a vida útil em comum; dificuldade de adaptação de decisões ao longo do tempo, pois novos riscos e incertezas podem necessitar alterações; e o excesso de disponibilidade de caixa no FC são reaplicadas pela taxa de custo de oportunidade.

O VPLA é o VPL periódico, ou seja, ao invés de um único VPL para todo o projeto, os ganhos são calculados anualmente (SOUZA, CLEMENTE, 2004; BROM, BALIAN, 2007). O VPLA, Equação (3) é transformado em uma serie uniforme, se o VPLA for maior que zero o projeto é viável (SOUZA; CLEMENTE, 2004).

Valor Presente Líquido Anualizado (VPLA) $=$ VPL $\frac{i \cdot(1+\mathrm{i})^{\mathrm{n}}}{\mathrm{i}-(1+\mathrm{i})^{\mathrm{n}}}$

O benefício do VPLA em referência ao VPL, está em poder avaliar melhor o ganho (LIMA, 2010).

\subsubsection{Taxa Interna Retorno (TIR) e Taxa Interna de Retorno Modificada (TIR-M)}

A TIR pode ser definida como sendo uma taxa de juros que faz com que o VPL se iguale a zero (CAVALCANTI; PLANTULLO, 2007). As vantagens da TIR (SAMPAIO FILHO, 2008): a) vincula-se ao VPL; b) considera o valor no tempo; e c) fácil interpretação. As desvantagens da TIR (BROM, BALIAN, 2007; SAMANEZ, 2009; FREZATTI, 2008): a) a inversão de sinais no FC podese encontrar mais de uma TIR; b) repetições dos FCs ocorrem na mesma TIR, onde a taxa pode ser sub ou superestimada; c) na análise de multiprojetos é 
necessário utilizar mais um método de avaliação. A TIR pode ser calculada conforme Equação (4) (SAMANEZ, 2009).

$$
\mathrm{VPL}=\sum_{\mathrm{t}=1}^{\mathrm{n}} \frac{\mathrm{PV}_{\mathrm{t}}}{(1+\mathrm{i})^{\mathrm{t}}}=0
$$

A TIR-M para Brom e Balian (2007, p. 28) propõe "[...] que os caixas gerados pelo projeto sejam reinvestidos pela taxa de atratividade e que as saídas [...], sejam reinvestidos pela taxa de juros de mercado de financiamento". Neste caso, a taxa média do investimento que iguala o fluxo de caixa (FREZATTI, 2008). As vantagens da TIR-M são: a) Normalmente, conduz a mesma decisão que o VPL; b) Fácil entendimento e transmissão; c) Resolve a questão das TIRs múltiplas; e d) Supera o pressuposto da taxa de reinvestimento da TIR. E como desvantagem pode conduzir a decisões indevidas em projetos mutuamente exclusivos (SAMPAIO FILHO, 2008).

\subsubsection{Payback simples, Payback descontado, Payback total, Payback TIR, Payback TIR Modificada}

$\mathrm{O}$ PB é o espaço de tempo em que ocorre o retorno do projeto, se o investimento se pagar no prazo estabelecido pode-se aceitar o investimento (BROM; BALIAN, 2007; SOUSA, 2007). Quanto menor, maior a liquidez do investimento e menor o risco (CAMLOFFSKI, 2014). O PB simples apresenta o tempo necessário para recuperar o capital principal sem utilizar taxa de desconto, amortiza-se o VP do empreendimento com as futuras entradas, na data zero (SOUSA, 2007). O PB descontado, além de recuperar o capital investido, considera o retorno mínimo exigido pelo investidor, as futuras entradas de caixa são trazidas a VP (BROM, BALIAN, 2007).

O PB total considera os fluxos de caixa após a data de recuperação, no intuito de apresentar um prazo de equilíbrio ao longo de todo projeto (BROM; BALIAN, 2007) e pode ser apurado por meio da Equação (5).

$$
\text { PB total }=\frac{\text { FC inicial }}{\sum \frac{\text { FC futuro }}{(1+\mathrm{i})^{\mathrm{n}}}} \times \text { número de anos }
$$

O PB TIR e PB TIR-M consideram a TIR como a taxa de juros e o prazo para recuperar o valor principal só ocorre quando o capital dobrar (BROM, BALIAN, 2007). Segundo Kassai et al. (2007) o PB TIR e PB TIR-M podem ser calculados da seguinte maneira: Inicia-se com a fórmula dos juros compostos e o tempo de recuperação é atingido quando $\mathrm{VP}=1$ e $\mathrm{FV}=2$, conforme Equação (6).

$$
\text { PB TIR-M }=\frac{\text { Logaritmo Neperiano (2) }}{\text { Logaritmo Neperiano (1+TIR-M) }}
$$




\subsubsection{Relação Custo-Benefício, Índice de Lucratividade (IL) e Taxa de Rentabilidade}

O índice custo-benefício "[...] é um indicador que resulta da divisão do valor atual dos benefícios pelo valor atual dos custos do projeto, incluindo o investimento inicial" (SAMANEZ, 2009, p. 39), e caso este índice for maior que um o investimento é economicamente viável. O custo-benefício expõe a previsão de ganho por unidade de capital investido em comparação aos ganhos que se teria na aplicação do valor da TMA, ele estima a rentabilidade total do investimento, e seu cálculo é realizado pela Equação (7) (SOUZA; CLEMENTE, 2004; LIMA, 2010).

$$
\text { Índice Custo-Benefício }=\frac{\sum_{\mathrm{t}=0}^{\mathrm{n}} \frac{\mathrm{b}^{\mathrm{t}}}{(1+\mathrm{K})^{\mathrm{t}}}}{\sum_{\mathrm{t}=0}^{\mathrm{n}} \frac{\mathrm{c}_{\mathrm{t}}}{(1+\mathrm{K})^{\mathrm{t}}}}
$$

Onde, $\mathrm{C} / \mathrm{B}=$ Índice Custo-Benefício; $\mathrm{bt}=$ Benefícios do Período $\mathrm{t} ; \mathrm{ct}=$ Custos do Período $\mathrm{t} ; \mathrm{K}=$ Custo do Capital; $\mathrm{n}=$ Horizonte do Planejamento.

O IL pode ser apurado, conforme Equação (8), pela divisão do VP das futuras entradas de caixa pelo VP das futuras saídas de caixa, se o resultado for maior que um, deve ser aceito, pois as entradas serão maiores que as saídas e o empreendimento irá gerar valor (BRANDÃO, 2010).

Índice de Lucratividade $=\frac{\mathrm{VP}(\text { Entradas de Caixa })}{\operatorname{VP}(\text { Saídas de Caixa })}$

O IL também indica, conforme Equação (9), quanto a VP dos fluxos de caixa futuro serão gerados para cada $R \$ 1,00$ investido, ele é obtido pela divisão da soma a VP e dos fluxos de caixa futuros, dividido pelo investimento inicial (BRUNI; FAMÁ, 2007).

$$
\text { Índice de Lucratividade }=\frac{\sum_{j}^{\mathrm{n}} \frac{\mathrm{FC} j}{(1+\mathrm{k})^{\mathrm{j}}}}{\text { Investimento Inicial }}
$$
Analisado.

Onde, FC = Fluxo de caixa no Período j; $\mathrm{k}=$ Custo do Capital $; \mathrm{j}=$ Período

A taxa de rentabilidade demonstra o retorno do investimento em percentagem, se for maior que um é atraente e pode ser apurada pela Equação (10) (KASSAI et al., 2007).

$$
\text { Taxa de Rentabilidade }=\frac{\text { VP }(\text { Entradas de Caixa })}{\text { VP }(\text { Saídas de Caixa })}-1
$$




\subsubsection{Retorno Adicional Sobre o Investimento (ROIA)}

O ROIA é “[...] uma medida de rentabilidade que nos dá o valor agregado à empresa pelo projeto, pois já expurga o efeito da TMA" (CAMLOFFSKI, 2014, p. 97). ROIA é a melhor avaliação de rentabilidade de um investimento, mede a riqueza gerada pelo empreendimento (SOUSA; CLEMENTE, 2004). O ROIA pode ser obtido pela Equação (11) (PENA; HOMMA; SILVA, 2011).

$$
\text { ROIA }=\left(\frac{\mathrm{FV}}{\mathrm{PV}}\right)^{\left(\frac{1}{\mathrm{n}}\right)-1}
$$

O ROIA “[...] enquanto índice de análise de investimento nivela por baixo a taxa de rendimento do projeto, apresentando uma leitura mais condizente com o percentual anual de ganhos em relação ao investimento inicial" (PENA; HOMMA; SILVA, 2011, p. 12)

\subsubsection{Taxa Média de Retorno (TMR) e Taxa Mínima de Atratividade (TMA)}

A TMRéa relação entre o valor ganho ou perdido em um empreendimento em relação ao valor investido (MACULAN; RIBEIRO, 2013). Esta taxa indica o retorno médio do investimento em determinado período (HASSEGAWA, 2009) e é um método simples e não considera o valor do dinheiro no tempo (GROPELLI; NIKBAKHT, 2002). O cálculo da TMR pode ser expresso por meio da Equação (12) (HASSEGAWA, 2009).

$$
\mathrm{TMR}=\frac{\text { Fluxo de caixa médio }}{\text { Investimento médio }}
$$

A TMR compara "[...] os lucros contábeis líquidos com os custos iniciais de um projeto, adicionando todos os lucros líquidos futuros e dividindo-os pelo investimento médio" (GROPELLI; NIKBAKHT, 2002, p. 133); e pode ser apurada pela Equação (13).

$$
\mathrm{TMR}=\frac{\text { média dos lucros líquidos anuais futuros }}{\text { metade do investimento inicial }}
$$

A aceitação ou não de um projeto pode ser decidida comparando-se a TMR e a taxa mínima de retorno aceitável (RESENDE; SIQUEIRA, 2004). Por sua vez, a TMA é definida como sendo o mínimo de retorno que um investimento deve gerar ao ser implantado (CAMLOFFSKI, 2014). A TMA também é considerada "[...] uma taxa que pode ser definida de acordo com a política de cada empresa. No entanto, a determinação ou escolha da TMA é de grande importância na decisão de alocação de recursos nos projetos de investimento" (SCHROEDER et al., 2005, p. 184).

As taxas que influenciam a TMA relacionam-se a taxa básica financeira, a taxa residual, a taxa de juros de longo prazo e a taxa do sistema especial de liquidação e custódia (SOUZA; CLEMENTE, 2004). 


\subsubsection{Método Monte Carlo (MMC)}

O MMC apurado por meio de softwares permite a visualização de um sistema real por meio de um exemplo matemático, com baixo custo e simples utilização (OLIVEIRA; ALMEIDA; REBELATTO, 2009).

A simulação de MMC viabiliza considerar diversas alternativas possíveis - sendo que os demais métodos fornecem uma quantidade restrita de opções - e também propicia uma distribuição estatística do VPL no investimento (BRANDÃO, 2010). Este autor detalha as seguintes etapas na sua apuração: a) Criar um modelo matemático dos fluxos de caixa e VPL; b) Identificar as incertezas do investimento e definir uma distribuição de probabilidade para cada uma, esta distribuição e seus critérios podem ser pelos históricos, por informações de mercado futuro ou experiência do analista; c) O software seleciona uma amostra aleatória de cada das variáveis a partir das distribuições determinadas, estes dados são utilizados para determinar o VPL do projeto; d) O software repete o processo milhares de vezes, assim obtém milhares de VPLs.

Segundo Samanez $(2009$, p. 148) “[...] o processo começa com a conversão de números aleatórios em observações das variáveis, a fim de determinar uma distribuição de probabilidade que se aproxime da distribuição real da variável". Este autor estratifica os seguintes passos: a) determinar todas as variáveis e equações para composição do fluxo de caixa, as equações devem espelhar as interdependências das variáveis; b) indicar as probabilidades de erro de previsão de cada parâmetro, e o tamanho do erro; e c) formar combinações entre os valores das distribuições de erros de previsão das variáveis, após calcular os fluxos de caixa resultantes, repetir o processo até obter um resultado mais preciso da distribuição de resultados possíveis.

\subsection{Análise de sensibilidade, riscos e incertezas dos investimentos}

A análise de sensibilidade possibilita constatar as variáveis críticas durante a projeção e determinação dos fluxos de caixa, permitindo avaliar o investimento considerando várias hipóteses em relação ao comportamento dessas variáveis (SAMANEZ, 2009). Uma alternativa é sensível a um parâmetro ou variável quando uma pequena modificação nestes indicadores resultar em mudança da decisão ou da alternativa (FERREIRA, 2009).

$\mathrm{O}$ risco faz parte do sistema devido à dificuldade em estabelecer todas as informações de um investimento e de possíveis mudanças (FIGUEIREDO et al., 2006). Estes autores ainda salientam que se for estabelecido o máximo, a média e o mínimo dessas variações e estas forem simuladas nos métodos determinados, é possível analisar os impactos.

Como as decisões são orientadas para o futuro, a interpretação do mesmo faz a diferença entre o sucesso e o fracasso, a possibilidade deste último ocorrer é que define o risco, esta probabilidade pode ser objetiva e subjetiva (BROM; BALIAN, 2007). Estes ainda classificam o risco como não sistêmico 
(diversificável), sendo controlável, e o risco sistêmico não sendo possível controlá-lo.

O tempo é um fator de risco, pois as decisões mais importantes têm reflexos no longo prazo, por isso que a decisão deve ser tomada com mais ênfase no futuro que no passado (SOUSA, 2007). Ferreira (2009) concorda que o foco deve ser o futuro, pois é difícil ocorrer o mesmo comportamento das variáveis no porvir da economia, já que os riscos sistêmicos contribuem significativamente para aumentar e diminuir riscos e incertezas.

Existem algumas medidas que podem diminuir o risco dos investimentos, conforme Kassai et al. (2007): a) Fazer avaliações quantitativas mesmo em projetos qualitativos, pois as formas que se tem para tratar o risco é na maioria quantitativa e determinística; b) Fazer estimativas cuidadosas, ou seja, ser prudente e conservador para elaborar projeções; c) Sempre fazer uma projeção otimista, uma pessimista e uma esperada, assim é possível analisar a sensibilidade ao risco de cada uma; d) Acrescer o risco à taxa de desconto e ajustar pela certeza equivalente, ou seja, trabalhar com fluxo de caixa descontado incorporando a taxa de risco na taxa de desconto; e) Realizar pesquisa de mercado pois possibilita saber os interesses dos consumidores; f) Utilizar a técnica de Delphi, ou seja, consultar um grupo de especialistas sem que os mesmos interajam entre si; g) Consultar especialistas que trabalhem em conjunto; h) Simular situações; i) Fazer analogias históricas e de fenômenos naturais; e j) Analisar os impactos cruzados, ou seja, o impacto de determinado evento com os demais eventos que se relaciona.

\section{PROCEDIMENTOS METODOLÓGICOS}

\subsection{Tipo de pesquisa}

Esta pesquisa quanto a abordagem do problema é quantitativa, pois “[...] caracteriza-se pelo emprego da quantificação tanto nas modalidades de coletas de informação, quanto no tratamento delas por meio de técnicas estatísticas [...]" (RICHARDSON, 1999, p. 70). Sendo assim, a apuração dos FC, a análise tradicional e, em especial, a estocástica de investimento foi realizado por meio de estatísticas.

A caracterização quanto ao objetivo geral esta pesquisa é descritiva, sendo esta "[...] a descrição das características de determinada população [...]" (GIL, 2010, p. 27). Se qualifica como tal, pois foram caracterizados e analisados diversos indicadores referentes a análise de viabilidade de investimento e descreve-se sua situação detalhada.

Os procedimentos técnicos relacionam-se a pesquisa documental primária e a entrevista despadronizada. A documental primária "[...] a fonte de coleta de dados está restrita a documentos, escritos ou não" (MARCONI; LAKATOS, 2010, p. 157). Já a entrevista despadronizada dirige a entrevista 
pela forma mais adequada, permitindo uma investigação mais desenvolvida das questões, as perguntas podem ser abertas e feitas em conversa informal (MARCONI; LAKATOS, 2010).

\subsection{Unidade de análise}

A unidade de análise deste estudo é a propriedade LJ de Westfália-RS. Esta propriedade atua com atividades agrícolas, mas tem interesse em iniciar a atividade de frango de corte, tem uma área de 8,2 hectares (FIGURA 1).

Figura 1 - Propriedade LJ, Westfália-RS

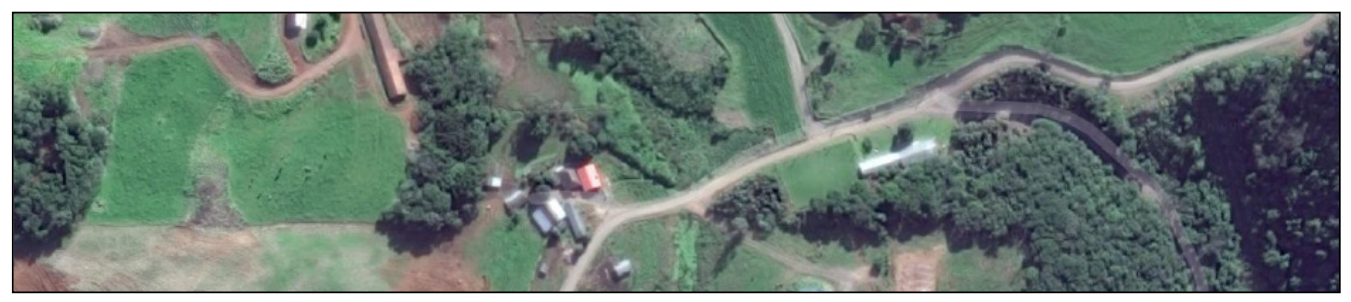

Fonte: Google Maps (2016).

\subsection{Coleta e análise dos dados}

Os dados foram coletados no período de outubro de 2015 a janeiro de 2016. As entrevistas ocorreram com o proprietário da LJ e Emater. As entrevistas direcionaram-se as seguintes questões, conforme pesquisas de Zanin et al. (2011), Casanova (2014) e Bianchini (2014): a) Quanto deseja retirar de pró-labore; b) Qual o gasto com luz; c) Qual o gasto com água; d) Qual o gasto com lenha; e) Gastos de manutenção; f) Gasto com casca e maravalha; g) Gasto no descarregamento dos pintos na chegada ao aviário; h) Gasto com a lavagem dos aviários; i) Gasto com compra de cal; j) Gasto com desinfecção dos aviários; e h) venda da cama de aviário (esterco).

A coleta de dados por meio da pesquisa documental primária ocorreu na Prefeitura Municipal de Westfália, na Emater/RS-Ascar, na integradora Alfa, na integradora Beta, na Lajeaves/NDB Comercio de Equipamentos Ltda, na Alles-Gut Comércio de Máquinas e Equipamentos Agrícolas, no Sicredi Ouro Branco, na Representações Francesquet, na Agroserrana Metalúrgica Ltda, na Agrocenter, na Tirp e Horst Consultoria Ambiental, com um técnico agropecuário da integradora Alfa, com o produtor interessado, na Futura Imóveis e no Tabelionato Teutônia e no cartório de Encantado.

A análise dos dados coletados iniciou-se com os fluxos de caixa, o qual foi a base para calcular VP, VPL, VPLA, TIR, M-TIR, PB simples, PB total, PB descontado, PB TIR, PB TIR-M, IL, ROIA, TMA e TMR. Estes cálculos foram efetuados em software Microsoft Office Excel 2013 e quando houve necessidade 
foi utilizado calculadora HP $12 \mathrm{C}$ e as fórmulas. Além disso foi utilizado o software Crystal Ball para o MMC. O Crystal Ball é uma planilha que modela previsões, simulações e otimizações, fornece informações sobre fatores de riscos (ORACLE, 2015).

\section{RESULTADOS E ANÁLISES}

\subsection{Elaboração do FC projetado}

A integradora Alfa permite a produção de 6,5 lotes por ano, o período médio de cada lote é de 38 dias, se este período for superior a 40 dias a integradora paga $R \$ 0,01$ a mais por dia/ave. A integradora fornece os pintos, a ração e assistência técnica, os quais são descontados na entrega dos lotes e o produtor recebe o valor líquido. A definição dos cenários na elaboração e projeção do FC (TABELA 1) relaciona-se com as informações constantes no relatório da Alfa em outubro de 2015, sendo classificados em: a) cenário pessimista: o menor valor pago pela alfa no mês por ave; $b$ ) realista: o valor médio pago no mês; b) otimista: o maior valor pago por ave no mês.

O FC projetado para 2017 apresentou-se negativo em todos os cenários, pois não ocorrem receitas apenas gastos financeiros, devido a compra da área de terra, a construção dos galpões e instalações dos equipamentos (APÊNDICE A). A projeção do FC na visão pessimista apresentou um saldo de caixa acumulado no período de 2017 a 2028 de $R \$-49.758,36$. Na situação realista e otimista em 2021, devido ao pagamento da primeira parcela do financiamento das instalações e equipamentos, o saldo do FC é menor que os anos precedentes (TABELA 1).

O saldo acumulado aplicado no FC ocorreu por meio da taxa de poupança de $7,582 \%$ ao ano (rendimento da poupança em fevereiro de 2016). O saldo de caixa acumulado no final do projeto no cenário realista é de R\$ 1.467.952,10, ocorrendo a aplicação dos saldos remanescentes em todos os períodos, ao final de 2028 , este tem um incremento de $41 \%$, já na visão otimista este valor é $44 \%$.

Tabela 1 - Resumo da projeção do FC, em reais

\begin{tabular}{|c|c|c|c|c|c|c|c|c|c|c|c|c|}
\hline & \multicolumn{3}{|c|}{2017} & \multicolumn{3}{|c|}{2018} & \multicolumn{3}{|c|}{2019} & \multicolumn{3}{|c|}{2020} \\
\hline & Pessimista & Realista & Otimista & Pessimista & Realista & Otimista & Pessimista & Realista & Otimista & Pessimista & Realista & Otimista \\
\hline $\begin{array}{l}\text { Receitas } \\
\text { operacionais }\end{array}$ & 0,00 & 0,00 & 0,00 & $79.153,68$ & $158.140,77$ & $207.507,69$ & $87.599,38$ & $175.014,39$ & $229.648,77$ & $96.946,23$ & $193.688,42$ & $254.152,29$ \\
\hline $\begin{array}{l}\text { (-) Gastos } \\
\text { operacionais }\end{array}$ & 0,00 & 0,00 & 0,00 & $48.903,06$ & $48.903,06$ & $48.903,06$ & $54.121,01$ & $54.121,01$ & $54.121,01$ & $59.895,72$ & $59.895,72$ & $59.895,72$ \\
\hline $\begin{array}{l}(-) \text { Gastos } \\
\text { financeiros }\end{array}$ & $26.010,00$ & $26.010,00$ & $26.010,00$ & $26.036,68$ & $26.036,68$ & $26.036,68$ & $26.066,20$ & $26.066,20$ & $26.066,20$ & $26.098,87$ & $26.098,87$ & $26.098,87$ \\
\hline $\begin{array}{l}\text { (=) Fluxo de } \\
\text { caixa }\end{array}$ & $-26.010,00$ & $-26.010,00$ & $-26.010,00$ & $4.213,95$ & $83.201,04$ & $132.567,96$ & $7.412,17$ & $94.827,18$ & $149.461,56$ & $10.951,64$ & $107.693,83$ & $168.157,70$ \\
\hline $\begin{array}{l}\text { Saldo } \\
\text { acumulado }\end{array}$ & $-26.010,00$ & $-26.010,00$ & $-26.010,00$ & $-21.796,05$ & $57.191,04$ & $106.557,96$ & $-14.383,88$ & $152.018,21$ & $256.019,52$ & $-3.432,24$ & $259.712,04$ & $424.177,22$ \\
\hline $\begin{array}{l}\text { Saldo } \\
\text { acumulado } \\
\text { Aplicação }\end{array}$ & 0,00 & 0,00 & 0,00 & 0,00 & $61.527,26$ & $114.637,19$ & 0,00 & $168.209,23$ & $284.122,71$ & 0,00 & $296.822,03$ & $486.572,31$ \\
\hline
\end{tabular}




\begin{tabular}{|c|c|c|c|c|c|c|c|c|c|c|c|c|}
\hline & \multicolumn{3}{|c|}{2021} & \multicolumn{3}{|c|}{2022} & \multicolumn{3}{|c|}{2023} & \multicolumn{3}{|c|}{2024} \\
\hline & Pessimista & Realista & Otimista & Pessimista & Realista & Otimista & Pessimista & Realista & Otimista & Pessimista & Realista & Otimista \\
\hline $\begin{array}{l}\text { Receitas } \\
\text { operacionais }\end{array}$ & $107.290,40$ & $214.354,98$ & $281.270,34$ & 118738,28 & $237.226,65$ & $311.281,88$ & $131.407,66$ & $262.538,74$ & $344.495,66$ & $145.428,85$ & $290.551,62$ & $381.253,35$ \\
\hline $\begin{array}{l}\text { (-) Gastos } \\
\text { operacionais }\end{array}$ & $66.286,60$ & $66.286,60$ & $66.286,60$ & 73359,38 & $73.359,38$ & $73.359,38$ & $81.186,82$ & $81.186,82$ & $81.186,82$ & $89.849,46$ & $89.849,46$ & $89.849,46$ \\
\hline $\begin{array}{l}(-) \text { Gastos } \\
\text { financeiros }\end{array}$ & $129.617,43$ & $129.617,43$ & $129.617,43$ & 93053,2 & $93.053,20$ & $93.053,20$ & $82.253,26$ & $82.253,26$ & $82.253,26$ & $71.458,03$ & $71.458,03$ & $71.458,03$ \\
\hline $\begin{array}{l}\text { (=) Fluxo de } \\
\text { caixa }\end{array}$ & $-88.613,63$ & $18.450,95$ & $85.366,32$ & $-47674,3$ & $70.814,07$ & $144.869,31$ & $-32.032,42$ & $99.098,66$ & $181.055,58$ & $-15.878,63$ & $129.244,14$ & $219.945,86$ \\
\hline $\begin{array}{l}\text { Saldo } \\
\text { acumulado }\end{array}$ & $-92.045,86$ & $278.163,00$ & $509.543,54$ & $-139720,16$ & $348.977,07$ & $654.412,84$ & $-171.752,58$ & $448.075,73$ & $835.468,42$ & $-187.631,21$ & $577.319,86$ & $1.055 .414,29$ \\
\hline \multirow[t]{3}{*}{$\begin{array}{l}\text { Saldo } \\
\text { acumulado } \\
\text { Aplicação } \\
\end{array}$} & 0,00 & $339.176,98$ & $615.303,01$ & 0,00 & $441.076,58$ & $817.808,58$ & 0,00 & $581.131,32$ & $1.074 .598,05$ & 0,00 & $764.236,13$ & $1.392 .696,23$ \\
\hline & \multicolumn{3}{|c|}{2025} & \multicolumn{3}{|c|}{2026} & \multicolumn{3}{|c|}{2027} & \multicolumn{3}{|c|}{2028} \\
\hline & Pessimista & Realista & Otimista & Pessimista & Realista & Otimista & Pessimista & Realista & Otimista & Pessimista & Realista & Otimista \\
\hline $\begin{array}{l}\text { Receitas } \\
\text { operacionais }\end{array}$ & $160.946,11$ & $321.553,48$ & $421.933,08$ & $178.119,06$ & $355.863,23$ & $466.953,34$ & $197.124,37$ & $393.833,84$ & $516.777,26$ & 218157,54 & $435.855,91$ & $571.917,39$ \\
\hline $\begin{array}{l}\text { (-) Gastos } \\
\text { operacionais }\end{array}$ & $99.436,39$ & $99.436,39$ & $99.436,39$ & $110.046,26$ & $110.046,26$ & $110.046,26$ & $121.788,19$ & $121.788,19$ & $121.788,19$ & 134782,99 & $134.782,99$ & $134.782,99$ \\
\hline $\begin{array}{l}\text { (-) Gastos } \\
\text { financeiros }\end{array}$ & $60.668,02$ & $60.668,02$ & $60.668,02$ & $49.883,81$ & $49.883,81$ & $49.883,81$ & $39.106,00$ & $39.106,00$ & $39.106,00$ & 762,55 & 762,55 & 762,55 \\
\hline $\begin{array}{l}\text { (=) Fluxo de } \\
\text { caixa }\end{array}$ & 841,69 & $161.449,06$ & $261.828,66$ & $18.188,99$ & $195.933,16$ & $307.023,27$ & $36.230,17$ & $232.939,64$ & $355.883,06$ & 82611,99 & $300.310,37$ & $436.371,85$ \\
\hline $\begin{array}{l}\text { Saldo } \\
\text { acumulado }\end{array}$ & $-186.789,52$ & $738.768,92$ & $1.317 .242,95$ & $-168.600,52$ & $934.702,09$ & $1.624 .266,22$ & $-132.370,35$ & $1.167 .641,73$ & $1.980 .149,28$ & $-49758,36$ & $1.467 .952,10$ & 2.416.521,13 \\
\hline $\begin{array}{l}\text { Saldo } \\
\text { acumulado } \\
\text { Aplicação }\end{array}$ & 0,00 & $995.870,63$ & $1.779 .970,97$ & 0,00 & $1.282 .166,36$ & $2.245 .230,14$ & 0,00 & $1.629 .981,34$ & $2.798 .329,61$ & 0,00 & $2.076 .646,43$ & $3.479 .956,53$ \\
\hline
\end{tabular}

Fonte: Elaborada pelos autores.

A análise dos FCs é que a taxa de atualização de valores foi de 10,67\%, e o valor dos juros dos financiamentos é fixo, indiferente desta variação e é um valor representativo de desembolsos. O que significa que a correção de 10,67 $\%$ não for aplicada ao longo do projeto, o montante final dos projetos pode sofrer impactos. Pois se a integradora não corrigir o valor pago por ave, nesta proporção de $10,67 \%$ ao ano esse o saldo projetado não se realiza.

\subsection{Análise tradicional de investimento}

A análise tradicional revela que o VP, acumulado no período, no cenário pessimista é de $R \$-73.196,12$, na conjuntura realista é de $R \$ 711.892,82$ e no otimista é de $\mathrm{R} \$ 1.202 .573,41$ (TABELA 2).

Tabela $2-\mathrm{VP}$, em reais

\begin{tabular}{l|c|c|c|c|r|c}
\hline & $\mathbf{2 0 1 7}$ & $\mathbf{2 0 1 8}$ & $\mathbf{2 0 1 9}$ & $\mathbf{2 0 2 0}$ & $\mathbf{2 0 2 1}$ & \multicolumn{1}{c}{$\mathbf{2 0 2 2}$} \\
\hline Pessimista & $-26.010,00$ & $3.807,67$ & $6.051,81$ & $8.079,59$ & $-59.071,89$ & $-28.716,71$ \\
\hline Realista & $-26.010,00$ & $75.179,39$ & $77.423,54$ & $79.451,32$ & $12.299,83$ & $42.655,01$ \\
\hline Otimista & $-26.010,00$ & $119.786,72$ & $122.030,86$ & $124.058,64$ & $56.907,16$ & $87.262,33$ \\
\hline & $\mathbf{2 0 2 3}$ & $\mathbf{2 0 2 4}$ & $\mathbf{2 0 2 5}$ & $\mathbf{2 0 2 6}$ & $\mathbf{2 0 2 7}$ & $\mathbf{2 0 2 8}$ \\
\hline Pessimista & $-17.434,53$ & $-7.809,15$ & 374,04 & $7.303,64$ & $13.145,32$ & $27.084,08$ \\
\hline Realista & $53.937,19$ & $63.562,57$ & $71.745,76$ & $78.675,36$ & $84.517,05$ & $98.455,80$ \\
\hline Otimista & $98.544,52$ & $108.169,90$ & $116.353,09$ & $123.282,69$ & $129.124,37$ & $143.063,13$ \\
\hline
\end{tabular}

Fonte: Elaborada pelos autores. 
Na conjuntura otimista o VPL e o VPLA demostram a viabilidade do investimento (TABELA 3). A análise de investimento realizada em propriedade de Nova Brescia-RS (Bianchini, 2014) revela um VPL negativo e em propriedade do oeste de Santa Catarina-SC (Zanin et al., 2011) o VPL é positivo em relação ao investimento em aviário de corte. Assim, percebe-se que dependendo do valor investido o VPL apresentado pode comportar-se tanto indicando a viabilidade como a inviabilidade do projeto.

Em relação a análise da TIR e da TIR-M, no cenário pessimista não revela retorno do investimento. Na simulação realista apresenta-se positiva, porém abaixo da taxa de retorno esperada e do custo de capital de $8,75 \%$, o que leva a inviabilidade do projeto. No cenário otimista o retorno está acima do estabelecido indicando a viabilidade neste cenário. No estudo de Zanin et al. (2011) a TIR se manteve abaixo de 6,7\% nas três propriedades estudas, concluindo-se que o retorno do investimento possui baixo percentual. Já no estudo de Miotelli (2013) realizado em Forquilhinha Santa Catarina e de Bianchini (2014) a TIR foi superior a TMA estabelecida, tornando viável os projetos.

Tabela 3 - Indicadores de viabilidade de investimento

\begin{tabular}{|c|c|c|c|}
\hline & Pessimista & Realista & Otimista \\
\hline VPL & $-\mathrm{R} \$ 971.880,18$ & - R\$ 186.791,24 & $\mathrm{R} \$ 303.889,35$ \\
\hline VPLA & $-\mathrm{R} \$ 147.350,45$ & $-\mathrm{R} \$ 28.320,13$ & $\mathrm{R} \$ 46.073,82$ \\
\hline TIR & $-20,01 \%$ & $6,91 \%$ & $15,98 \%$ \\
\hline TIR-M & $-19,02 \%$ & $7,95 \%$ & $18,17 \%$ \\
\hline PB simples & Inexistente & 9 anos e 10 meses & 7 anos 3 meses \\
\hline PB descontado & Inexistente & Inexistente & 9 anos 9 meses \\
\hline PB total & Inexistente & 14 anos 7 meses & 9 anos \\
\hline PB TIR & Inexistente & 10 anos 4 meses & 4 anos 8 meses \\
\hline PB TIR-M & Inexistente & 9 anos e 1 mês & 4 anos 2 meses \\
\hline IL (VP entradas / VP saídas) & 0,82 & 1,63 & 2,14 \\
\hline IL (soma dos vp/investimento) & $-0,08$ & 0,79 & 1,34 \\
\hline Taxa de Rentabilidade & $-18,36 \%$ & $63,11 \%$ & $114,02 \%$ \\
\hline $\begin{array}{l}\text { ROIA pelo IL } \\
\text { (VP entradas / VP saídas) }\end{array}$ & $-0,02$ & $4,161 \%$ & $6,55 \%$ \\
\hline $\begin{array}{l}\text { ROIA pelo IL } \\
\text { (soma dos vp / investimento) }\end{array}$ & Inexistente & $-1,92 \%$ & $2,46 \%$ \\
\hline ROIA pela fórmula & 0,968348089 & 0,515103107 & 0,52744549 \\
\hline TMR & $-46,14 \%$ & $13,61 \%$ & $22,41 \%$ \\
\hline TMA & $17,67 \%$ & $17,67 \%$ & $17,67 \%$ \\
\hline
\end{tabular}

Fonte: Elaborada pelos autores. 
No estudo de Bianchini (2014) o PB descontado é aproximadamente 10 anos, o que o faz concluir que o projeto é viável. Casanova (2014) revela que o tempo de retorno é 5,48 anos e também conclui a viabilidade do projeto e para Miotelli (2013) o prazo é em torno de 5 anos, este concluiu que devido ao aumento do consumo de carne de frango é viável. Ao comparar estes estudos com o PB neste projeto em questão, o tempo de retorno do estudo analisado é mais elevado, apenas o PB descontado no cenário otimista se aproxima do estudo de Bianchini (2014). Assim percebe-se que dependendo da região e da integradora o tempo de retorno varia.

O IL demostra na visão pessimista para cada $R \$ 1,00$ de saída se tem $R \$$ 0,82 de entrada, ou seja, é inviável. Já na visão realista tem-se 1,63 de entrada para cada $R \$ 1,00$ de saída, nesta situação o projeto é viável. E no cenário otimista para cada $R$ \$1,00 de saída, há $R$ \$2,14 de entrada, o que torna o investimento viável. O IL obtém na visão pessimista um valor de $R \$-0,08$, o que significa que para cada $R \$ 1,00$ se tem uma perda de $R \$ 0,08$. Na percepção realista se tem um retorno de $R \$ 0,89$ para cada $R \$ 1,00$ investido e no cenário otimista o retorno é de $\mathrm{R} \$ 1,34$, demostrando que somente na percepção otimista, pois o mínimo de retorno, para cada $R \$ 1,00$ investido é de $R \$ 1,00$ de retorno. Bianchini (2014) obteve um IL maior que 1, o que o fez concluir que o projeto é viável.

A taxa de rentabilidade indica viabilidade nas percepções realista e otimista. No estudo de Casanova (2014) realizado em Marau-RS, a taxa de rentabilidade foi de 19,02\%, concluindo que seu projeto é viável.

Na visão pessimista só existe ROIA pela fórmula nas demais maneiras de calcular não gera retorno. No cenário realista, calculando-se o ROIA pelo IL (VP entradas / VP saídas) apresenta retorno, pelo IL (soma dos VP / investimento) não há retorno e sim perda, justamente pelo fato do valor presente dos fluxos de caixa ser menor que o investimento. Na percepção otimista segue a mesma lógica que a realista, porém com um maior retorno, sendo no IL (VP entradas / VP saídas) e há retorno no IL (soma dos VP / investimento).

A TMR comprova que no cenário pessimista se tem perda com o investimento. Na percepção realista a TMR é positiva, porém é menor que a TMA e na otimista é maior que a TMA apontando para a viabilidade do projeto. A TMA do projeto foi definida como sendo a soma da inflação de 2015 mais o rendimento da poupança em fevereiro de 2016.

Analisando-se os indicadores na integradora Alfa, em seu conjunto, pois é praticamente impossível permanecer num cenário só durante a vida do projeto, provavelmente será transitado diversas vezes em cada um deles. Junto com isso deve-se ponderar a fragilidade econômica e sua perspectiva para o futuro devido ao elevado valor investido. Mesmo que no cenário otimista o projeto seja viável, nas demais simulações é inviável e não há como saber em qual cenário o estudo vai estar enquadrado, de modo geral, ele apresenta-se inviável. 


\subsection{Análise estocástica do investimento}

O software Crystal Ball é uma ferramenta que realiza cálculos e análises precisas, pois consegue quantificar as incertezas do projeto devido a sua capacidade de realizar até 200.000 avaliações. Na realização da simulação do MMC pelo software Crystal Ball considerou-se o investimento inicial de R\$ $898.684,06$, permitindo que o mesmo chegue a 998.684,00. Também se estima um prazo de retorno em 9, 10 e 11 anos e a TMA estimado foi de $15 \%, 17 \%$ e $20 \%$. A simulação ocorreu conjecturando-se a média dos fluxos de caixa nos 3 cenários e o desvio padrão (TABELA 4).

Tabela 4 - Estatística descritiva

\begin{tabular}{c|c|c}
\hline Cenário & Média do FC & Desvio padrão \\
\hline Pessimista & $-4.146,53$ & $31.920,58$ \\
\hline Realista & $135.814,74$ & $77.102,62$ \\
\hline Otimista & $201.376,76$ & $85.984,31$ \\
\hline Média & $\mathbf{1 1 1 . 0 1 4 , 9 9}$ & $\mathbf{6 5 . 0 0 2 , 5 1}$ \\
\hline
\end{tabular}

Fonte: Elaborada pelos autores.

A simulação do MMC revela que o VPL médio é de R\$ - 437.980,49 numa análise conjunta dos três cenários propostos (GRÁFICO 1).

Gráfico 1 - Frequência do VPL

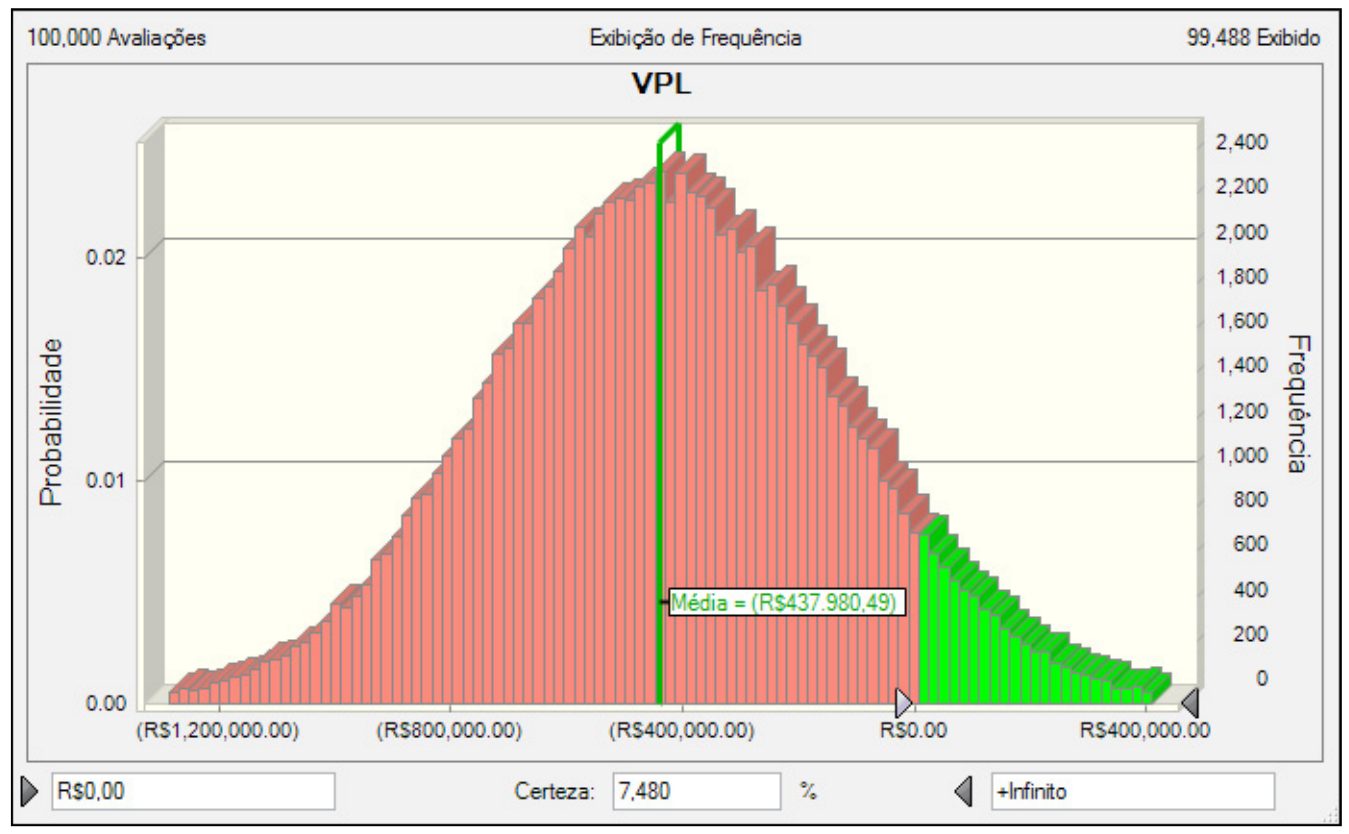

Fonte: Software Crytal Ball. 
A possibilidade do VPL apresentar-se negativo é de 92,52\% em relação aos $7,48 \%$ de ser positivo, sendo assim, o investimento pode ser considerado inviável.

\section{CONCLUSÃO}

A análise de investimento deve ser realizada conjuntamente pelo método tradicional e estocástico, pois o segundo complementa as informações relacionadas ao risco e as incertezas quantificando-as melhorando assim a tomada de decisão do analista. Diante disto, os resultados deste estudo revelamse variados, de acordo com o cenário, O VPL na pessimista e realista ficou negativo e no otimista foi de $\mathrm{R} \$ 303.889,35$. A TIR só é atrativa na simulação otimista, sendo que na pessimista é negativa. $\mathrm{O}$ PB descontado inexiste na visão pessimista e realista, já na otimista é quase de 10 anos. O IL é de 1,34 no cenário otimista, nos demais é menor que 1 e o ROIA é de 4,16\% na visão pessimista.

Mesmo que nos métodos tradicionais analisou-se três cenários em cada integradora para diminuir os riscos. Não há uma análise que entrelace as três visões, que seria a prática do dia a dia, pois os resultados oscilam e ficam variando entre os três cenários; sendo assim, este fato torna a tomada de decisão complexa. Diante disto, o Crystal Ball faz esse relacionamento entre os cenários, assim consegue dar uma resposta consistente e rápida, diminuindo consideravelmente a informação subjetiva relacionada ao risco.

A comparação das informações geradas pela análise de investimento tradicional com a estocástica do Crystal Ball revela que na segunda não é necessário efetuar o cálculo de diversos índices, oferece resultados consistentes. Portanto, com base na análise tradicional e estocástica o investimento é inviável. E como o investimento em questão não é viável, recomenda-se ao interessado buscar outra alternativa, de preferência que o valor investido seja menor, já que o mesmo depende de financiamento e o cenário econômico atual encontra-se frágil.

\section{REFERÊNCIAS}

AMORIM, Danilo E.; ROCHA, Frederico S. Análise de projetos de investimento sob incerteza: uma aplicação de opções reais. Revista de Opinião, 2011.

ANDRADE, Marciel. Cadeia de valor e vantagens competitivas: um estudo sobre a cadeia produtiva avícola da região do Vale do Taquari. 2015. Dissertação (Mestrado) - Curso de Pós-graduação em Administração, Centro Universitário UNISC, Santa Cruz do Sul, 25 jun. 2015.

BIANCHINI, Bruno J. Estudo de viabilidade financeira na implantação de um aviário modelo dark house em uma propriedade rural no município de Nova Bréscia. 2014. Monografia (Graduação) - Curso de Administração, Centro Universitário UNIVATES, Lajeado, 2014. 
BRANDÃO, Luiz. Avaliação de projetos e empresas. Apostila Brandão, Pontifícia Universidade Católica do Rio de Janeiro, 2010. Disponível em: <http:/ / www.iag.pucrio.br/ brandao/ADM1387/Apostila\%20Brandao\%20ADM\%201387\%202010.1.pdf>. Acesso em: 20 set. 2015.

BROM, Luiz G.; BALIAN José E. A. Análise de investimentos e capital de giro: conceitos e aplicações. São Paulo: Saraiva, 2007.

BRUNI, Adriano L.; FAMÁ, Rubens. As decisões de investimentos: com aplicações na HP12C e Excel. 2. ed. São Paulo: Atlas, 2007.

BRUNI, Adriano L.; FAMÁ, Rubens; SIQUEIRA, José de O. Análise do risco na avaliação de projetos de investimento: uma aplicação do Método de Monte Carlo. Caderno de pesquisas em administração, v.1, n. 6, p. 1-14, 1998.

CAMLOFFSKI, Rodrigo. Análise de investimentos e viabilidade financeira das empresas. São Paulo: Atlas, 2014.

CASANOVA, Tássia. Estudo de viabilidade para ampliação de um empreendimento avícola no município de Marau. 2014. Monografia (Graduação) - Curso de Ciências Contábeis, Universidade de Passo Fundo, Passo Fundo, 2014.

CAVALCANTI, Marly; PLANTULLO, Vicente L. Análise e elaboração de projetos de investimento de capital sob uma nova ótica. Curitiba: Juruá, 2007.

FERREIRA, Roberto G. Engenharia econômica e avaliação de projetos de investimento: critérios de avaliação, financiamentos e benefícios fiscais, análise de sensibilidade e risco. São Paulo: Atlas, 2009.

FIGUEIREDO, Adelson M. et al. Integração na criação de frangos de corte na microrregião de Viçosa - MG: viabilidade econômica e análise de risco. Revista de economia e sociologia rural, v. 44 n. 4, p. 714-730, 2006.

FREZATTI, Fábio. Gestão da viabilidade econômico-financeira dos projetos de investimento. São Paulo: Atlas, 2008.

GIACOMIN, Jacksson H. Estudo de viabilidade econômico-financeira de uma microcervejaria no estado de Santa Catarina. 2008. Monografia (Graduação) - Curso de Ciências Econômicas, Universidade federal de Santa Catarina, Florianópolis, 2008.

GIL, Antônio C. Como elaborar projetos de pesquisa. 5. ed. São Paulo: Atlas, 2010.

GOOGLE, Maps. Disponível em:<https: / /www.google.com.br/maps/@-29.3947343,$51.7656967,296 \mathrm{~m} /$ data=!3m1!1e3>. Acesso em: 10 maio 2016.

GROPELLI, A. A.; NIKBAKHT Ehsan. Administração financeira. Tradução Célio k. Moreira. Revisão Técnica de João C. Douat. 2. ed. São Paulo: Saraiva, 2002. 
HASSEGAWA, Toshikazu. Metodologia para determinação da viabilidade econômica de sistema de informação. Curitiba, 2009. Disponível em: <http:/ / www.batebyte. pr.gov.br/modules/conteudo/conteudo.php?conteudo=1390>. Acesso em: 20 out. 2015.

HOFER, Elza et al. A relevância do controle contábil para o desenvolvimento do agronegócio em pequenas e médias propriedades rurais. Revista de Contabilidade e Controladoria, v. 3, n. 1, p. 27-42, 2011.

KASSAI, José R. et al. Retorno de investimento: abordagens matemática e contábil do lucro empresarial. 3. ed. rev. ampl. São Paulo: Atlas, 2007.

LIMA, José D. de. Proposição de um sistema de planejamento da produção olerícola nas unidades de produção familiar. 2010. Tese (Doutorado) - Curso Engenharia da Produção, Universidade Federal do Rio Grande do Sul, Porto Alegre, 2010.

LIMA, Luiz C.; GIASSON, Oldair R. Avaliação dos investimentos em empresa avícola. Repositório Roca, 2013. Disponível em: <http:/ / repositorio.roca.utfpr.edu. br/jspui/ bitstream/1/1479/1/PB_EGCF_VII_2012_19.pdf>. Acesso em: 20 set. 2015.

MACULAN, Cleber; RIBEIRO, Ivano. Análise de retorno de investimento em oficina mecânica. CAP Accounting and Management, n. 7, v. 7, p. 223-235, 2013.

\section{MARCONI, Marina de A.; LAKATOS, Eva M. Fundamentos de metodologia} científica. 7. ed. São Paulo: Atlas, 2010.

MIOTELLI, Luciano R. Estudo da viabilidade na ampliação da criação de frango de corte para um integrado da empresa Seara. 2013. Monografia (Graduação) - Curso de Administração, Universidade do Extremo Sul Catarinense, UNESC, Criciúma, 2013.

OLIVEIRA, Mario H. da F.; ALMEIDA, Mariana R. de; REBELATTO, Daisy A. do N. Avaliação de investimentos sob condições de incerteza: a aplicação do Método de Monte Carlo em um estudo de caso no setor sucroalcoleiro. In: XXIX ENCONTRO Nacional de Engenharia de Produção, Salvador, out. 2009.

ORACLE. Oracle Crystal Ball. 2015. Disponível em: <http:/ / www.oracle.com/br/ products / applications/crystalball/overview/index.html>. Acesso em: 12 out. 2015.

PAIXÃO, Roberto B.; BRUNI, Adriano L.; MARBACK, Heitor. Aperfeiçoando decisões de investimento com o crystal ball. In: $1^{\circ}$ ENCONTRO Norte-Nordeste de Finanças, Recife, set. 2004.

PEDRAZZI, Diogo R.; VIEIRA, Saulo F. A. O processo de tomada de decisão de investimentos de capital nas micro, pequenas e médias empresas: um estudo de caso do setor metalúrgico de Londrina-PR. Revista Facesi, v. 1, n. 1, p. 1-8, 2009.

PENA, Heriberto W. A.; HOMMA, Alfredo K. O.; SILVA, F. L da. Análise de viabilidade econômica: um estudo aplicado a estrutura de custo da cultura do dendê 
no estado do Pará-Amazônia-Brasil. Revista acadêmica da Universidade Málaga, n. 11, p. 1-24, 2011.

RESENDE, Marcio de A.; SIQUEIRA, José R. M. de. Orçamento de capital: uma exposição de aspectos relevantes e dos cuidados em sua utilização. Convibra, 2004. Disponível em: <http:/ / www.convibra.com.br/2004/pdf/115.pdf>. Acesso em: 20 out. 2015.

RICHARDSON, Roberto J. Pesquisa Social: métodos e técnicas. 3. ed. São Paulo: Atlas, 1999.

SAMANEZ, Carlos P. Engenharia econômica. São Paulo: Pearson Prentice Hall, 2009.

SAMPAIO FILHO, Antonio C. de S. Taxa interna de retorno modificada: proposta de implementação automatizada para cálculo em projetos não-periódicos, não necessariamente convencionais. 2008. Dissertação (Mestrado), Curso Profissionalizante em Administração, Faculdade de economia e finanças IBMEC, Rio de Janeiro, 30 jul. 2008.

SCHROEDER, Jocimari T. et al. O custo de capital como taxa mínima de atratividade na avaliação de projetos de investimento. Revista Gestão Industrial, v. 1, n. 2, p. 3645, 2005.

SOUSA, Almir F. Avaliação de investimentos: uma abordagem prática. São Paulo: Saraiva, 2007.

SOUZA, Alceu; CLEMENTE, Ademir. Decisões financeiras e análise de investimentos: fundamentos, técnicas e aplicações. 5. ed. São Paulo: Atlas, 2004.

ZAGO, Camila A.; WEISE, Andreas D.; HORNBURG, Ricardo A. A importância do estudo de viabilidade econômica de projetos nas organizações contemporâneas. Convibra, 2009. Disponível em: <http:/ / www.convibra.org/2009/artigos/142_0. pdf>. Acesso em: 07 set. 2015.

ZANATA, Alexandre. Análise de investimento. Blog Alexandre Zanata, 16 jan. 2012. Disponível em: <http:/ / alexandrefzanata.blogspot.com.br/2012/01/analise-deinvestimento_16.html>. Acesso em: 07 set. 2015.

ZANCHET, Mateus J. A Importância da BR 386 para o desenvolvimento do Vale do Taquari. 2013. Monografia (Graduação) - Curso de Geografia, Universidade Regional do Noroeste do Estado do Rio Grande do Sul, fev. 2013.

ZANIN, Antonio et al. Viabilidade econômica e financeira da atividade avícola: estudo de casos em propriedades rurais. In: $4^{\circ}$ CONGRESSO UFSC de Controladoria e Finanças. Florianópolis, 18 a 20 abr. de 2011.

ZDANOWICZ, José Eduardo. Gestão financeira para cooperativas: de produção, consumo, crédito e demais sociedades. Porto Alegre: Evangraf, 2010. 


\section{Apêndice A}

Tabela 3 - Investimento inicial

\begin{tabular}{|c|c|c|}
\hline Descrição & Quantidade/medida & Valor Total \\
\hline Silo 16 toneladas Tecnoesse & 2 Unidades & $\mathrm{R} \$ 12.000,00$ \\
\hline Comedouro automático Tecnoesse & 1152 Unidades & $\mathrm{R} \$ 72.000,00$ \\
\hline Bebedouro Nipple & 2 Conjuntos & $\mathrm{R} \$ 45.000,00$ \\
\hline Cortinado completo & 2 Conjuntos & $\mathrm{R} \$ 48.000,00$ \\
\hline Ventilador Tecnoesse & 48 Unidades & $\mathrm{R} \$ 17.280,00$ \\
\hline Sistema de Nebulização & 2 Unidades & $\mathrm{R} \$ 600,00$ \\
\hline Tela malha 2 , arrame 18 & $1344 \mathrm{~m} 2$ & $\mathrm{R} \$ 11.424,00$ \\
\hline $\begin{array}{l}\text { Sistema elétrico com quadro de comando e máquina } \\
\text { de cortina automática }\end{array}$ & 2 Conjuntos & $\mathrm{R} \$ 38.000,00$ \\
\hline Aquecedor & 2 Unidades & $\mathrm{R} \$ 36.000,00$ \\
\hline Máquina de levantamento guinchos & 2 Unidades & $\mathrm{R} \$ 2.400,00$ \\
\hline Arco de desinfecção automático & 2 Unidades & $\mathrm{R} \$ 6.400,00$ \\
\hline Comedouro infantil $5 \mathrm{KG}$ & 280 Unidades & $\mathrm{R} \$ 2.800,00$ \\
\hline Timer analógico & 2 Unidades & $\mathrm{R} \$ 76,00$ \\
\hline Carrinho lança chamas 2 botijões & 1 Unidade & $\mathrm{R} \$ 450,00$ \\
\hline Madeira para tablado & 2 Unidades & $\mathrm{R} \$ 12.000,00$ \\
\hline Removedor de cama & 1 Unidade & $\mathrm{R} \$ 4.500,00$ \\
\hline Tela malha 5 , arame 16 & $800 \mathrm{~m} 2$ & $\mathrm{R} \$ 5.000,00$ \\
\hline Estrutura metálica completa & 2 Conjuntos & $\mathrm{R} \$ 302.400,00$ \\
\hline Mão de obra & - & $\mathrm{R} \$ 30.000,00$ \\
\hline Escritório & 1 Unidade & $\mathrm{R} \$ 15.000,00$ \\
\hline Composteira & 1 Unidade & $\mathrm{R} \$ 2.200,00$ \\
\hline Cercamento & - & $\mathrm{R} \$ 11.000,00$ \\
\hline Subtotal máquinas e equipamentos & & $\mathrm{R} \$ 674.530,00$ \\
\hline Área de terra & 8,2 Hectares & $\mathrm{R} \$ 212.000,00$ \\
\hline Despesas pré-operacionais & Onde & Valor Total \\
\hline Projeto para a Licença Prévia (LP) & $\begin{array}{c}\text { Tirp e Horst Consultoria } \\
\text { Ambiental }\end{array}$ & $\mathrm{R} \$ 300,00$ \\
\hline $\begin{array}{l}\text { Anotação de Responsabilidade Técnica (ART Crea- } \\
\text { RS) da LP }\end{array}$ & $\begin{array}{c}\text { Tirp e Horst Consultoria } \\
\text { Ambiental } \\
\end{array}$ & $\mathrm{R} \$ 67,68$ \\
\hline Licença Prévia (válida por um ano) & $\begin{array}{c}\text { Prefeitura Municipal de } \\
\text { Westfália }\end{array}$ & $\mathrm{R} \$ 348,32$ \\
\hline Projeto para a Licença de Instalação (LI) & $\begin{array}{c}\text { Tirp e Horst Consultoria } \\
\text { Ambiental }\end{array}$ & $\mathrm{R} \$ 300,00$ \\
\hline $\begin{array}{l}\text { Anotação de Responsabilidade Técnica (ART Crea- } \\
\text { RS) da LI }\end{array}$ & $\begin{array}{c}\text { Tirp e Horst Consultoria } \\
\text { Ambiental } \\
\end{array}$ & $\mathrm{R} \$ 67,68$ \\
\hline Licença de Instalação (válida por um ano) & $\begin{array}{c}\text { Prefeitura Municipal de } \\
\text { Westfália }\end{array}$ & $\mathrm{R} \$ 293,90$ \\
\hline Projeto para a Licença de Operação (LO) & $\begin{array}{c}\text { Tirp e Horst Consultoria } \\
\text { Ambiental }\end{array}$ & $\mathrm{R} \$ 300,00$ \\
\hline
\end{tabular}




\begin{tabular}{l|c|r}
\hline Descrição & Quantidade/medida & Valor Total \\
\hline $\begin{array}{l}\text { Anotação de Responsabilidade Técnica (ART Crea- } \\
\text { RS) da LO }\end{array}$ & $\begin{array}{c}\text { Tirp e Horst Consultoria } \\
\text { Ambiental }\end{array}$ & $\mathrm{R} \$ 67,68$ \\
\hline Licença de Operação (válida por quatro anos) & $\begin{array}{c}\text { Prefeitura Municipal de } \\
\text { Westfália }\end{array}$ & $\mathrm{R} \$ 118,18$ \\
\hline Certidão Negativa de Débitos & $\begin{array}{c}\text { Prefeitura Municipal de } \\
\text { Westfália }\end{array}$ & $\mathrm{R} \$ 12,44$ \\
\hline Imposto sobre a Transmissão de Bens Imóveis (ITBI) & $\begin{array}{c}\text { Prefeitura Municipal de } \\
\text { Westfália }\end{array}$ & $\mathrm{R} \$ 1.060,00$ \\
\hline Escritura Publica & Tabelionato & $\mathrm{R} \$ 1.500,00$ \\
\hline Taxas para Registrar a Matrícula & Registro de Imóveis & $\mathrm{R} \$ 1.200,00$ \\
\hline Supressão de Vegetação & $\begin{array}{c}\text { Prefeitura Municipal de } \\
\text { Westfália }\end{array}$ & $\mathrm{R} \$ 85,53$ \\
\hline Terraplanagem & $\begin{array}{c}\text { Prefeitura Municipal de } \\
\text { Westfália }\end{array}$ & $\mathrm{R} \$ 3.060,00$ \\
\hline Projeto Técnico para a Instituição Financeira & Ascar/Emater-RS & $\mathrm{R} \$ 3.372,65$ \\
\hline Subtotal & & $\mathrm{R} \$ 12.154,06$ \\
\hline Total do investimento & & $\mathrm{R} \$ \mathbf{8 9 8 . 6 8 4 , 0 6}$ \\
\hline
\end{tabular}

